University of New Hampshire

University of New Hampshire Scholars' Repository

Natural Resources and the Environment

Scholarship

Natural Resources and the Environment

$11-2014$

\title{
Maximum likelihood parametric reconstruction of forest vertical structure from inclined laser quadrat sampling.
}

Mark J. Ducey

University of New Hampshire, mark.ducey@unh.edu

Follow this and additional works at: https://scholars.unh.edu/nren_facpub

Part of the Forest Sciences Commons

\section{Recommended Citation}

Ducey, M.J. Maximum likelihood parametric reconstruction of forest vertical structure from inclined laser quadrat sampling. (2014) International Geoscience and Remote Sensing Symposium (IGARSS), art. no. 6947632, pp. 5052-5055. doi: 10.1109/IGARSS.2014.6947632

This Article is brought to you for free and open access by the Natural Resources and the Environment at University of New Hampshire Scholars' Repository. It has been accepted for inclusion in Natural Resources and the Environment Scholarship by an authorized administrator of University of New Hampshire Scholars' Repository. For more information, please contact Scholarly.Communication@unh.edu. 


\title{
MAXIMUM LIKELIHOOD PARAMETRIC RECONSTRUCTION OF FOREST VERTICAL STRUCTURE FROM INCLINED LASER QUADRAT SAMPLING
}

\author{
Mark J. Ducey \\ University of New Hampshire \\ Department of Natural Resources and the Environment \\ 114 James Hall, Durham, NH 03824 USA
}

\begin{abstract}
Forest vertical structure is critical to ecological function, and provides a crucial link to air- and spaceborne remote sensing (including LiDAR), but is difficult to measure from the ground. Laser point quadrat sampling has been suggested as one alternative, but previous statistical approaches to modeling forest structure using such data have required impractical sample sizes. Here, I develop the theory for maximum likelihood estimation of a parametric model of forest vertical structure, and illustrate it using inclined point quadrat sampling with a handheld laser. Results from three forest stands in arctic Norway suggest excellent qualitative agreement with structure derived from alternative methods. The approach generalizes readily to other hardware configurations, including terrestrial laser scanning.
\end{abstract}

Index Terms - Ground-based remote sensing, forest structure, LiDAR, terrestrial laser scanning

\section{INTRODUCTION}

The vertical structure of forests, and the density of foliar display within that structure, is critical for understanding tree and stand level productivity and carbon sequestration [1], water and energy transfer [2,3], and surface attributes such as albedo [4]. Quantifying forest vertical structure has emerged as an important objective for remote sensing applications, and airborne and spaceborne LiDAR has been widely used for this purpose [5, 6, 7].

The collection of ground-based reference data for such remote sensing applications remains challenging. A variety of field techniques are available, but most are labor-intensive, imprecise, or yield results that can be challenging to interpret $[8,9,10]$. Terrestrial LiDAR has emerged as a promising tool for this task (e.g. $[11,12,6]$ ) but the scanners themselves remain expensive. For extensive field campaigns, and especially for those in remote or difficult terrain, there is a need for approaches that use compact, lightweight, and inexpensive equipment without undue labor costs.

This work is a scientific contribution of the New Hampshire Agricultural Experiment Station.
In the past decade, some studies (e.g. [8]) have suggested the use of handheld laser rangefinders, in an adaptation of MacArthur and Horn's point quadrat sampling methods [13, 14]. However, enthusiasm for this approach has been dampened by the very large sample sizes that appear to be needed for stable estimates [8]. More recently, a connection between the traditional MacArthur and Horn approach and the family of statistical techniques known as survival analysis has been identified [15], potentially opening the door to more efficient use of point quadrat sampling data such that reliable estimates are possible with much smaller sample sizes. The MacArthur-Horn estimator of foliage density, often applied to both conventional LiDAR data as well as vertical laser quadrat samples, is identical to a nonparametric estimator of the hazard function in survival analysis. Recognition of the connection between the foliage density profile and problems in survival analysis allows the foliage density estimation problem to be embedded in a regression context, facilitating site-specific modeling and hypothesis testing as well as allowing the introduction of covariates [15].

\section{THEORY}

Previous work using handheld laser rangefinders (e.g. [8, 15])has emphasized vertically-oriented measurement. Here, I build on the statistical framework of [15], and suggest an adaptation to inclined laser quadrat sampling, which has applications not only for sampling with a single probe angle (as with a handheld rangefinder) but also to multiple angles (as with most terrestrial laser scanners).

\subsection{Inclined Laser Quadrat Sampling}

Warren Wilson [16, 17] developed the classic theory of inclined quadrat sampling. Following [16], let $\alpha$ be the inclination of a plant surface to the horizontal in degrees, $\beta$ be the inclination of a hypothetical infinitesimally narrow, linear probe to the horizontal, let $f(h)$ be the density of plant surfaces $\left(\mathrm{m}^{2} / \mathrm{m}^{3}\right)$ at height $h$, and let $f_{\beta}(h)$ be the "apparent density," or the density of the projections of plant surfaces onto the plane normal to a probe with angle $\beta$. Furthermore, 
let $\eta$ be the radial orientation of the plant surface ( $\eta=0$ corresponding to north) and $\zeta$ be the corresponding orientation of the probe. If the angle $\eta-\zeta$ is uniform on $[0,360]$, the following relation holds for $\alpha \leq \beta$ :

$$
\frac{f_{\beta}(h)}{f(h)}=\cos \alpha \sin \beta
$$

and for $\alpha>\beta$,

$$
\frac{f_{\beta}(h)}{f(h)}=\left[\frac{2}{\pi} \sin \alpha \cos \beta \sin \zeta_{0}+\left(1-\frac{\zeta_{0}}{90}\right) \cos \alpha \sin \beta\right]
$$

where $\zeta_{0}$ is the angle between 0 and 90 that satisfies $\zeta_{0}=$ $\cos ^{-1}(\cot \alpha \tan \beta)$. Although the original derivation assumes $\eta$ is uniform on [0,360], from a design-based sampling perspective if $\zeta$ is uniform on $[0,360]$ then the condition $\eta-\zeta$ is uniform on $[0,360]$ also holds irrespective of the distribution of $\eta$ in the plant population.

One approach to the use of equations 1 and 2 is to allow $\beta$ to vary (often over the entire hemisphere) and to invert a parametric or nonparametric model for the distribution of $\alpha$. This approach underlies most attempts to estimate leaf area index from passive sensors or hemispherical photography [9]. Alternatively, Warren Wilson $[16,17]$ shows that estimates can be obtained from a limited selection of values of $\beta$ without the need to consider the distribution of $\alpha$ explicitly. In particular, when $\beta=32.5$ degrees,

$$
\hat{f}(h)=1.1 \hat{f}_{32.5}(h)
$$

is very nearly a minimax estimator of $f(h)$, having a maximum error of 10 percent when the distribution of $\alpha$ is degenerate at $\alpha=0$ or $\alpha=90$. In practice, distributions of $\alpha$ are mixtures that include angles neither strictly horizontal nor vertical, so the error is considerably less.

In the original derivation for inclined point quadrats $[16,17]$, it was assumed that densities would be estimated from a count of contacts along each probe. This could be done, in principle, from narrow-beam full-waveform LiDAR (with appropriate detection of multiple returns). However, for the purposes of this study, we assume a first-return probe. The basic theory for recovering profiles from first-return data was originally developed by MacArthur and Horn [13], and has been used with optical probes [14] and lasers [8], with $\beta=90$. Although theoretically sound, the MacArthur and Horn approach returns unstable estimates, especially in dense canopies, and requires very large sample sizes (in the thousands) [8]. More recently, the MacArthur and Horn approach has been shown to be identical with the nonparametric Kaplan-Meier [18] estimate of a cumulative hazard function, with $f(h)$ serving the role of the hazard [15]. An alternative estimator suggested by [8] is identical with the Nelson-Aalen [19] estimator of the cumulative hazard. Both the Kaplan-Meier and Nelson-Aalen estimators are flexible but extremely data-demanding. Alternative approaches using standard survival analysis regression techniques are able to recover overall plant area density in a more stable fashion, but are not flexible in the profiles produced [15].

\subsection{Maximum Likelihood Analysis}

As an alternative, let us consider direct estimation of $f(h)$ by maximum likelihood. Let the total density of plant surfaces be $L,\left(\mathrm{~m}^{2} / \mathrm{m}^{2}\right)$, let $G(h \mid \theta)$ be its cumulative distribution function (CDF) with unknown parameters $\theta$, and let $g(h \mid \theta)$ be the corresponding probability density function (PDF). Thus, $f(h)=L g(h \mid \theta)$.

We consider two types of probes. Probes that are uncensored travel from a known point of origin (the instrument location, $h_{0}$ ) and strike a plant surface. Probes that are censored do not strike plant material, but are terminated either by striking material that is not of interest (such as the ground) or by escaping the canopy entirely. Let $\delta_{i}$ be an indicator function for the $i^{t h}$ probe; $\delta_{i}=0$ for an uncensored probe, and $\delta_{i}=1$ if the probe is censored. For both uncensored and censored probes, denote the height at which the probe terminates as $h_{i}$, and let the distance traveled by the probe be $l_{i}$. On level terrain, $l_{i}=\left(h_{i}-h_{0}\right) / \sin \beta$; a simple trigonometric adjustment is appropriate on most sloping terrain.

For an ensemble of $n$ independent probes, we can write the likelihood function as the product of the probabilities associated with the individual probes. First, assuming locally planar (but not necessarily level) terrain, let

$$
S_{i}=\exp \left[-\frac{l_{i}}{h_{i}-h_{0}} \int_{h_{0}}^{h_{i}} f_{\beta}(h) \mathrm{d} h\right]
$$

be the probability that a probe survives unobstructed from $h_{0}$ to $h_{i}$, and

$$
s_{i}=-\left.\frac{\mathrm{d} S_{i}}{\mathrm{~d} h}\right|_{h=h_{i}}=\frac{l_{i}}{h_{i}-h_{0}} S_{i} f_{\beta}\left(h_{i}\right)
$$

Then the overall log-likelihood can be written as:

$$
\ln \Lambda=\sum_{i=1}^{n} \delta_{i} \ln S_{i}+\left(1-\delta_{i}\right) \ln s_{i}
$$

Maximization of $\ln \Lambda$ over the unknown parameters $L$ and $\theta$ yields a natural estimate of the vertical profile of plant matter. Strictly speaking, equations 4 and 5 incorporate the unknown distribution of plant surfaces $\alpha$ through the dependence of $f_{\beta}$ on that distribution (equations 1 and 2). In principle, the angular distribution could also be parameterized (and either assumed constant with $h$, or varying over $h$ ) and those parameters could also be recovered in the likelihood maximization step. However, recognizing the nearly constant relationship between $f_{32.5}(h)$ and $f(h)=L g(h \mid \theta)$ in eq. 3, we may substitute $f_{32.5}(h)=L g(h \mid \theta) / 1.1$ in equations 4 and 5 in the 
case of probes inclined at a 32.5 degree angle. In that case, we obtain the following simplifications:

$$
\ln S_{i}=-L k_{i}\left[G\left(h_{i} \mid \theta\right)-G\left(h_{0} \mid \theta\right)\right]
$$

and

$$
\ln \Lambda=\ln S_{i}+\left(1-\delta_{i}\right)\left[\ln \left|k_{i}\right|+\ln L+\ln g(h \mid \theta)\right]
$$

where $k_{i}=\frac{l_{i}}{1.1\left(h_{i}-h_{0}\right)}$. Thus, estimation of the unknown parameters $L$ and $\theta$ becomes straightforward for any parametric distribution with a closed-form CDF and PDF.

\section{FIELD EXAMPLE}

\subsection{Site Description and Methods}

To illustrate the approach, data were collected in three forest stands in arctic Norway during the peak growing season of 2012. Sites were located between $69.440^{\circ}$ and $69.632^{\circ}$ latitude and $17.441^{\circ}$ and $20.335^{\circ}$ longitude in low-stature birch woodland. The Lyngsdalselva site was a tall but open forest with trees and shrubs of varying height on nutrient-poor, excessively well-drained glacial outwash; the Mefjordvaer stand had a shorter, closed canopy and was situated on moderatelytextured soils with understory vegetation suggesting a more nutrient-rich site; while the Koppangen site was located on marginal soils and heavily influenced by domestic grazing. In all three stands, a cluster of four sample points was installed, slope and aspect were recorded for each point, and conventional forest biometric measurements (including tree diameter, height, and crown length) were performed. A Leica DISTO $^{\mathrm{TM}}$ rangefinder, mounted on a camera tripod, was used to take inclined laser probes at an inclination angle of $32.5^{\circ}$. Probes were taken every $15^{\circ}$ radially about the tripod position in the upward direction, and every $30^{\circ}$ radially in the downward direction, for a total of 36 probes at each tripod position and 144 probes per stand. Using the built-in live-view camera in the laser, strikes were recorded as plant material, ground, or sky.

For each stand, the vertical profile of plant material was estimated by maximizing the log-likelihood (equation 8 ), assuming a beta mixture model:

$$
\begin{aligned}
g(x)= & \frac{p}{B\left(\theta_{1}, \theta_{2}\right)} x^{\theta_{1}-1}(1-x)^{\theta_{2}-1} \\
& +\frac{1-p}{B\left(\theta_{3}, \theta_{4}\right)} x^{\theta_{3}-1}(1-x)^{\theta_{4}-1}
\end{aligned}
$$

where $x=h / h_{\max }, \theta=\left\{\theta_{1}, \theta_{2}, \theta_{3}, \theta_{4}, p\right\}$ is a vector of unknown parameters, and $B$ is the beta function. The maximum height $h_{\max }$ was taken as the height of the tallest tree in the vicinity of the sample points within each stand.

\subsection{Results}

Results for the three example stands are shown in Figure 1. Qualitatively, the structural results agree well with field observations, both in terms of the relative density and height distribution of canopy elements. The beta mixture model was flexible enough to capture the roughly unimodal vertical distribution of tree and tall shrub canopies at Lyngsdalselva and Koppangen and the denser, more continuous canopy at Mefjordvaer, along with the dense low understory layer that was present at all three sites. Site conditions prevented destructive sampling (e.g. vertically stratified clip-and-weigh techniques; [14]). However, the profiles for overstory trees and shrubs conform well to those predicted using a basal areaweighted allocation of canopy elements to the live canopy interval of conventionally measured trees (not shown).
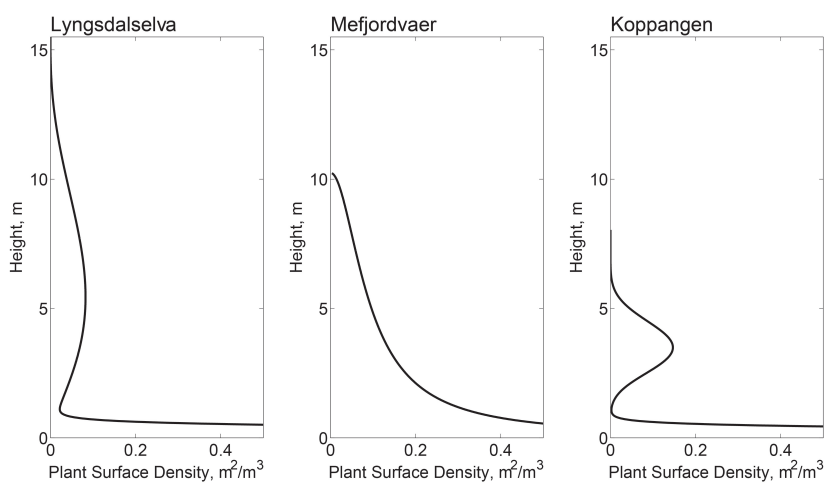

Fig. 1. Apparent foliage density profiles for three low-stature arctic birch forests in northern Norway.

\section{DISCUSSION AND CONCLUSIONS}

Maximum likelihood estimation offers the potential for more efficient use of laser quadrat data, including more stable estimates of canopy structure with smaller sample sizes than had previously been considered necessary [8]. In part, this is due to the ability to use a simplified parametric model in place of a data-demanding nonparametric estimator [15]. Although not explored here, the use of covariates could provide additional stability, and open the door to the use of laser quadrat data in a hypothesis-testing framework [15].

As with other indirect, non-contact approaches to estimation of canopy structure, the derivations employed here depend on an independence assumption that leads to bias in the presence of clumping. However, combination of this approach with existing correction methods for shoot- and canopy-level clumping may help address this issue, as has previously been demonstrated for estimation of total plant area index with hemispherical photography and passive radiation sensors [9]. Moreover, the methods addressed here explicitly deal with the issue of foliage angle distribution, 
which may be a major source of bias in optical and laserbased vertical point quadrat methods $[14,8]$. The vertical angle used in those methods has been identified as the most sensitive to differences in angular orientation of foliage and other plant surfaces $[16,17]$.

In practice, the methods outlined here offer the possibility of ground-based measurement of vertical structure of tall canopies using inexpensive, highly portable devices. This creates the possibility of more direct correlation with forest profiles derived from airborne and spaceborne LiDAR than would be possible using traditional biometric methods, or where the expense, availability, or environmental sensitivity of terrestrial laser scanners would make their use impossible. However, the basic modeling framework, with a suitable model for the angular distribution of foliage and other plant surfaces, can easily be adapted to the multiple probe angles available from terrestrial laser scanner data. Alternatively, it can be used to model the vertical profile of horizontallyprojected canopy elements when probes are oriented in a strictly vertical fashion, as in previous work with handheld laser rangefinders $[8,15]$, or single-return air- or spaceborne LiDAR [7]. The full development of the technique, including its extension to include covariates derived from conventional ground or remotely sensed data, is an ongoing area of work.

\section{REFERENCES}

[1] R.H. Waring, "Estimating forest growth and efficiency in relation to canopy leaf area," Adv. Ecol. Res., vol. 13, pp. 327-354, 1983.

[2] D.Y. Hollinger, "Canopy organization and foliage photosynthetic capacity in a broad-leaved evergreen montane forest," Funct. Ecol., vol. 3, no. 1, pp. 53-62, 1989.

[3] D.D. Baldocchi, K.B. Wilson, and L. Gu, "How the environment, canopy structure and canopy physiological functioning influence carbon, water and energy fluxes of a temperate broad-leaved deciduous forest - an assessment with the biophysical model CANOAK," Tree Physiol., vol. 22, pp. 1065-1077, 2002.

[4] F.B. Sullivan, S.V. Ollinger, M.E. Martin, M.J. Ducey, L.C. Lepine, and H.F. Wicklein, "Interrelations among leaf and canopy nitrogen and optical and structural traits of New Hampshire forests," Can. J. For. Res., vol. 43, no. 1, pp. 18-27, 2013.

[5] S.A. Hall, I.C. Burke, D.O. Box, M.R. Kaufmann, and J.M. Stoker, "Estimating stand structure using discretereturn lidar: an example from low density fire prone ponderosa pine forests.," For. Ecol. Manage., vol. 208, pp. 189-209, 2005.

[6] N.C. Coops, T. Hilker, M. Wulder, B. St-Onge, G. Newnham, A. Siggins, and J.A. Trofymow, "Estimat- ing canopy structure of douglas-fir forest stands from discrete-return LiDAR," Trees, vol. 21, pp. 295-310, 2007.

[7] M. van Leeuwen and M. Nieuwenhuis, "Retrieval of forest structural parameters using LiDAR remote sensing," Eur. J. For. Res., vol. 129, pp. 749-770, 2010.

[8] P.J. Radtke and P.V. Bolstad, "Laser point-quadrat sampling for estimating foliage-height profiles in broadleaved forests," Can. J. For. Res., vol. 31, pp. 410-418, 2001.

[9] I. Jonckheere, S. Fleck, K. Nackaerts, B. Muys, P. Coppin, M. Weiss, and F. Baret, "Review of methods for in situ leaf area index determination: Part I. theories, sensors and hemispherical photography," Ag. For. Meteorol., vol. 121, pp. 19-35, 2004.

[10] D. Seidel, S. Fleck, C. Leuschner, and T. Hammett, "Review of ground-based methods to measure the distribution of biomass in forest canopies," Ann. For. Sci., vol. 68, no. 2, pp. 225-244, 2011.

[11] J.L. Lovell, D.L.B. Jupp, D.S. Culvenor, and N.C. Coops, "Using airborne and ground-based ranging lidar to measure canopy structure in Australian forests," Can. J. Remote Sens., vol. 29, pp. 1-16, 2003.

[12] G.G. Parker, D.J. Harding, and M.L. Berger, "A portable LiDAR system for rapid determination of forest canopy structure," J. Appl. Ecol., vol. 41, pp. 755-767, 2004.

[13] R.H. MacArthur and H.S. Horn, "Foliage profile by vertical measurements," Ecology, vol. 50, pp. 802-804, 1969.

[14] J.D. Aber, "A method for measuring foliage-height profiles in broad-leaved forests," J. Ecol., vol. 67, pp. 3540, 1979.

[15] D.S. Maynard, M.J. Ducey, R.G. Congalton, and J. Hartter, "Modeling forest canopy structure and density by combining point quadrat sampling and survival analysis," For. Sci., vol. 59, no. 6, pp. 681-692, 2013.

[16] J. Warren Wilson, "Inclined point quadrats," New Phytol., vol. 59, no. 1, pp. 1-8, 1960.

[17] J. Warren Wilson, "Estimation of foliage denseness and foliage angle by inclined point quadrats," Aust. J. Bot., vol. 11, pp. 95-105, 1963.

[18] E.L. Kaplan and P. Meier, "Nonparametric estimation from incomplete observations," J. Am. Stat. Assoc., vol. 53, pp. 457-481, 1958.

[19] W. Nelson, "Theory and applications of hazard plotting for censored failure data," Technometrics, vol. 14, pp. 945-966, 1972. 